Article

\title{
Heritage Building Information Modeling (H-BIM) Applied to A Stone Bridge
}

\author{
Carlos A. León-Robles ${ }^{1}{ }^{(\mathbb{D}}$, Juan F. Reinoso-Gordo ${ }^{1, *(\mathbb{D})}$ and Juan J. González-Quiñones ${ }^{2} \mathbb{C}$ \\ 1 Department Architectural and Engineering Graphic Expression, University of Granada, 18071 Granada, \\ Spain; cleon@ugr.es \\ 2 TargetPix, 18015 Granada, Spain; juanjogonqui@gmail.com \\ * Correspondence: jreinoso@ugr.es
}

Received: 31 December 2018; Accepted: 25 February 2019; Published: 1 March 2019

\begin{abstract}
Certain historical works of civil engineering should be preserved as heritage monuments and when possible should continue serving the function they were designed for. Old stone bridges could be sustainably maintained but their conservation requires accurate documentation. In this study, we have scanned Ízbor bridge (1860) in Spain, and to facilitate conservation, we have modeled the ancient bridge using BIM (building information modeling). We propose a method and a model for this kind of bridge to be used as a reference for similar heritage monuments. Ízbor bridge modeled in this way will be useful for government planning and conservation agencies.
\end{abstract}

Keywords: BIM; H-BIM; laser scanner; maintenance and conservation; Civil Engineering

\section{Introduction}

The development of heritage building information modeling (H-BIM) can be used to record such features as the geometry, materials, textures, and relationships between features of a historical monument [1,2]. Thus, H-BIM can help enable us to reconstruct the monument in case of damage or disappearance and to manage its conservation during the operation and maintenance phases, including the end of its service life with demolition and recycling, if its conservation is not possible [3,4]. Nevertheless, H-BIM may not be suitable or recommendable for all types of historical monuments, a debate which is treated in other studies [5,6]. The complexity involved in historical heritage modelling using BIM (building information modelling) software makes the H-BIM an emerging technology that helps us to understand, document, and digitally manage historical monuments [7]. We need to take into account that this software is only one tool in the BIM process [8].

Surveying, by providing the texture and geometry of a monument, begins the H-BIM modeling process. This has resulted in the development of topographic and conventional modeling techniques [9], leading to the newest methods [10,11]. Currently, laser scanning [12,13] and photogrammetry [14] are the main techniques used to record the geometry and texture of an existing infrastructure, giving rise to a textured point cloud (PC). On the one hand, terrestrial laser scanner (TLS) has been widely used in archeology and building $[15,16]$, this approach becoming steadily more versatile due the smaller size and lighter weight of the equipment. TLS captures a textured PC in a short period of time with the desired accuracy, setting the angular step between the points captured. Nevertheless, the singular geometry of each monument and the visibility restricted to scan the entire monument from a single scanner position make it necessary to register multiple overlapping scans of a single PC. The registration problem can be solved in two different ways: (a) knowing the position of each scanning using the total station and/or GPS if PC georeferencing is needed $[17,18]$ or $(b)$ by pattern-recognition algorithms [19]. 
On the other hand, for many years, historical heritage has been studied using conventional point-by-point photogrammetric techniques [20]. Currently, this method is performed by software based on the concept structure from motion (SfM) [21] and the SIFT algorithm [22]. These two survey techniques provide the accuracy needed to capture the geometry and deformations that occur over time, as well as the current state of the texture, both being key for surveying historical heritage [23].

This research presents a bridge-modelling workflow, taking into account the nature and peculiarity of these kinds of bridges, with the goal of cataloging and preserving them. Thus, because this research focuses on bridge modeling, we refer to it as "historical bridge information modelling" (HBrIM). However, as the BIM process should be as standardized and made as comprehensive as possible, we call this process "H-BIM". For this, we analyzed the bridge spanning the Ízbor river in the province of Granada (Spain). Usually, this kind of historical monument has no technical documentation that could direct effective management or conservation works.

The Ízbor bridge is located in the Betic mountain range, which has notable geotechnical instability and high seismicity. This situation has triggered several pathologies in the old bridges which are still in service, requiring conservation measures to prevent their collapse. Some examples of these pathologies include: (a) The bridge over the Bayacas river in Órgiva, where a metal brace structure had to be built to prevent the arch from collapsing (Figure 1a); (b) the bridge over the Válor river, where the sides of have been reinforced with metal straps (Figure 1b); (c) the bridge over the Viñas river, also in Válor, where one of the arches has already fallen and been replaced by a modern concrete plank (Figure 1c). The fact that the Ízbor Bridge is better conserved than the other three bridges prompted us to choose it to formulate an H-BIM and propose its management, thereby preventing it from becoming a ruin like the others.

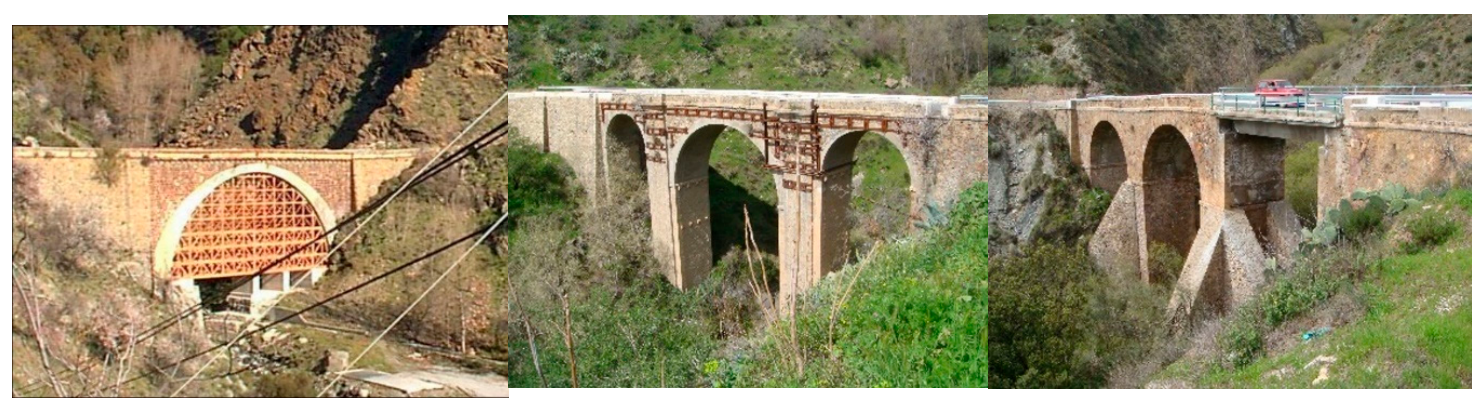

(a)

(b)

(c)

Figure 1. Examples of bridges, near Ízbor bridge, which present certain pathologies. (a) A bridge over the Bayacas river in Órgiva. (b) A bridge over the Válor river. (c) A bridge over the Viñas river.

History and Description of Ízbor Bridge

At the end of the 18th century, a bridge was built over the Ízbor river to connect the towns of Lanjarón and Vélez de Benaudalla in the province of Granada. However, this bridge served only the passage of muleteers, not being apt for other purposes due to its structure. This restricted the economic development of the province because it was the only point that did not allow the transport of goods and source materials between the capital, Granada, and the port, Motril. Recognizing the benefit for the province that would result from making it possible for carriages to cross the Ízbor river, the engineer of the Ministry of Public Works Juan de la Cruz Fuentes drafted the project of construction of a new stone bridge (Figure 2) on June 1, 1859 (during the reign of Isabel II), which was approved by the Royal Order of March 16, 1860. The construction of the bridge was finished in 1866. 


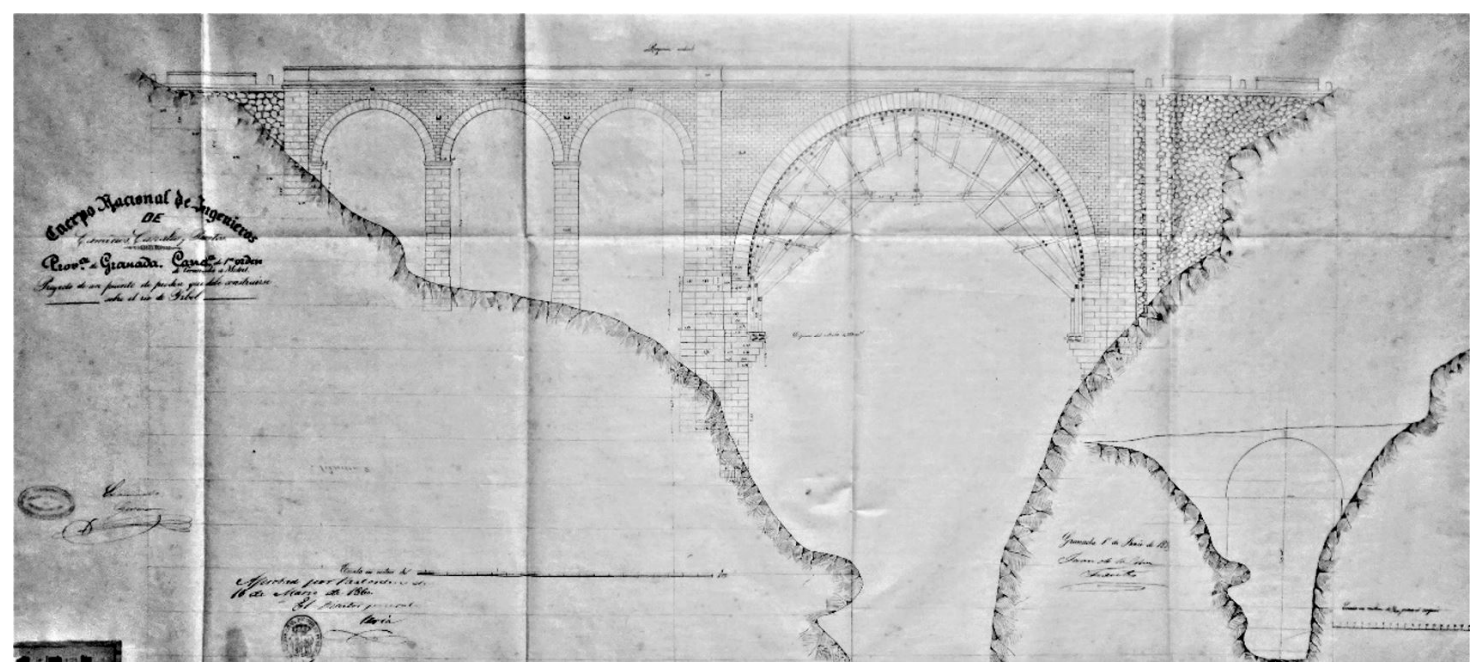

(a)

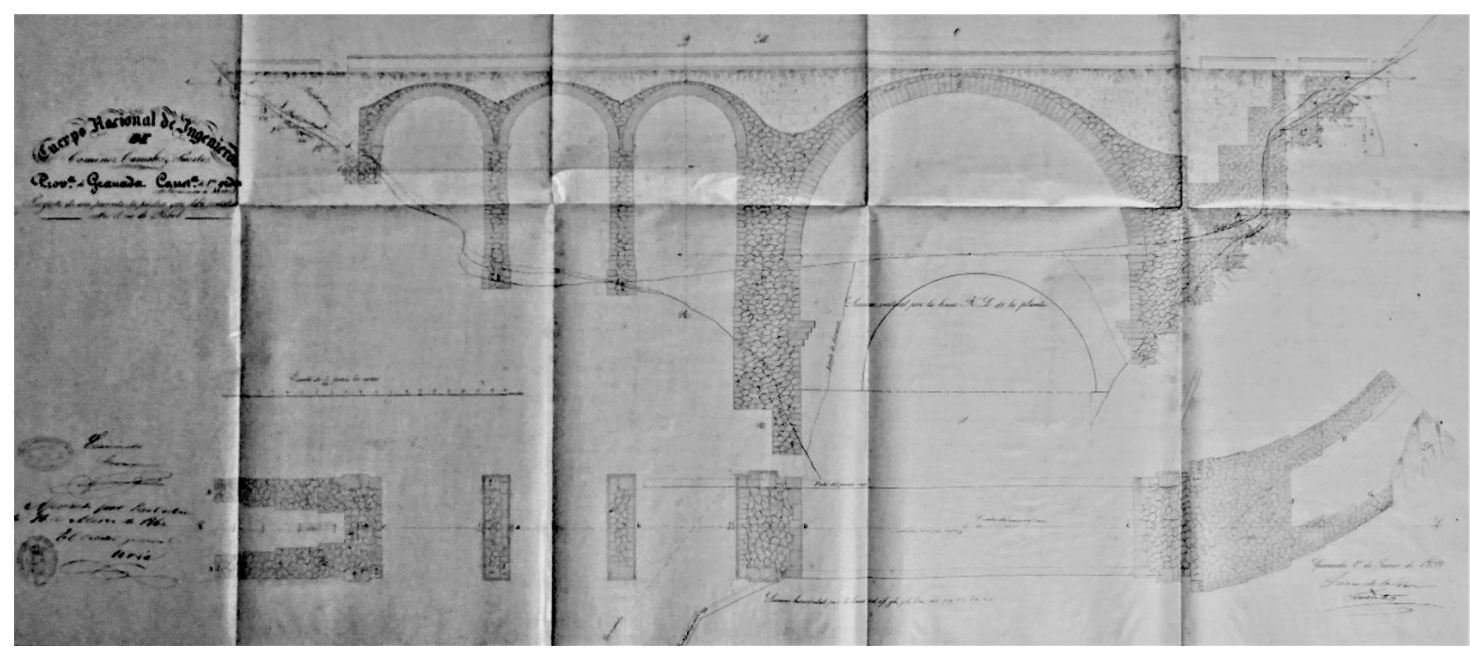

(b)

Figure 2. Ízbor bridge plans. (a) Upstream elevation. (b) Middle section.

Because of the rugged orography, the geotechnical complexities, and the high seismicity of the Betic mountains, the area was exhaustively surveyed in order to find the most suitable site for the new bridge. Finally, the engineer chose the same site that had been used for the 18th-century bridge. The improved layout of the new road, both in plan and elevation, meant that the new bridge would be higher than the previous one (Figure $2 b$ shows the position of both bridges): the older bridge stood 29 $\mathrm{m}$ above the riverbed, the new bridge $45 \mathrm{~m}$. The remains of the 18th-century bridge are still visible today, having served as a base for the scaffolding of the new bridge (Figure 3).

The river cross-section shows the right bank to be extremely steep, almost vertical; nevertheless, the left bank has a small plateau which led the engineer to divide the bridge into two parts: (a) The first part rests on the plateau and is composed of three round arches made of brick, each with a $7.17 \mathrm{~m}$ span and being $0.68 \mathrm{~m}$ thick, the spandrel wall areas of each arch being composed of stone masonry for aesthetic appeal. (Figure 4 Zone a). (b) The second part consists of a single round stone-masonry arch with a $23 \mathrm{~m}$ span and being $1.10 \mathrm{~m}$ thick (Figure 4 Zone b). Regarding the project author, the mentioned first part could have been made by two stone arches with major length but this option was more expensive than the other option, and it was not executed. 


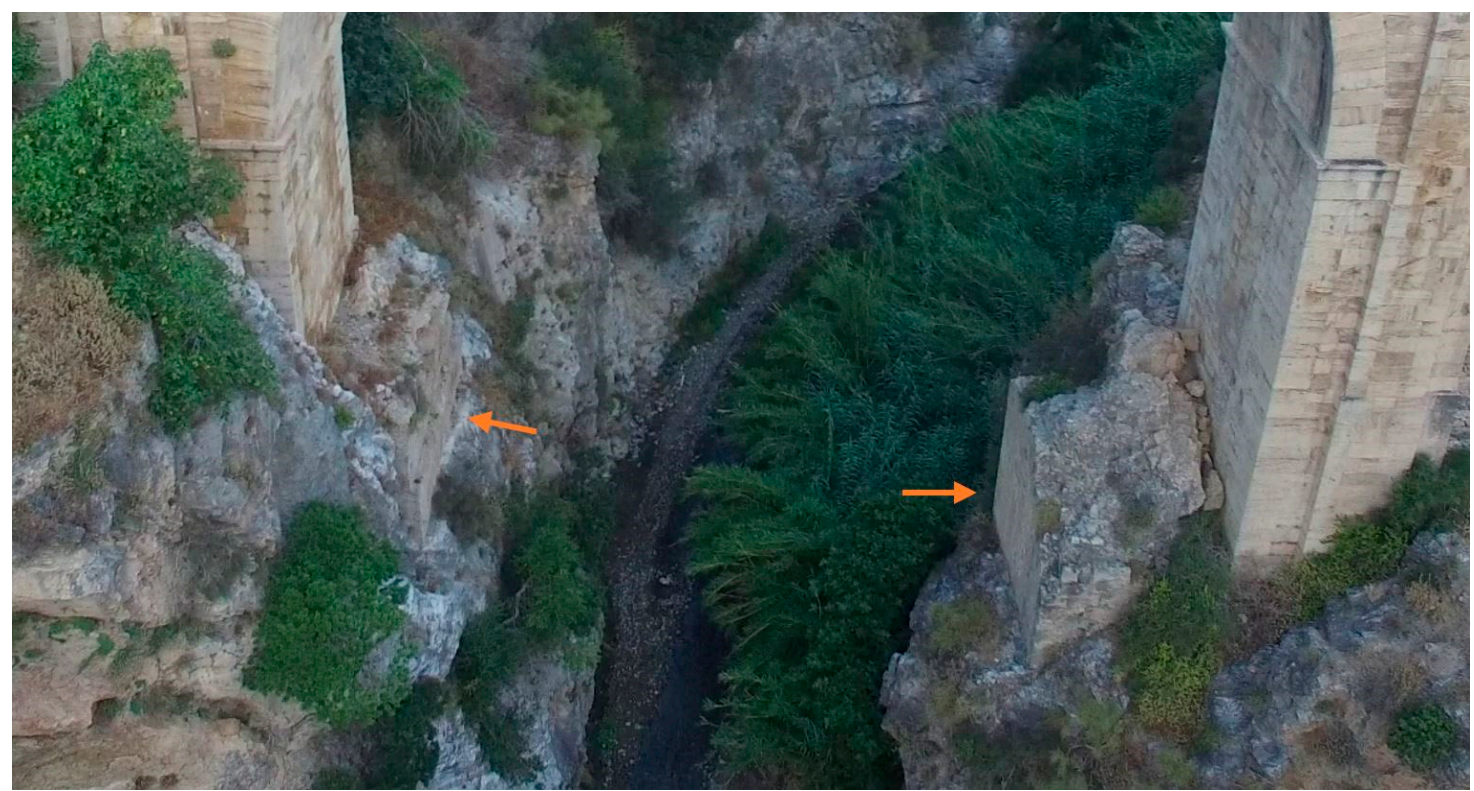

Figure 3. Orange arrows indicate the remains of the 18th-century bridge.

The piers of the new bridge measure $10.54 \mathrm{~m}$ in maximum height, while the highest abutment stands $13.53 \mathrm{~m}$. Both the piers and the abutments are $6.80 \mathrm{~m}$ thick and were built of ordinary masonry, using finished stonework in the parts open to view. The project plans (Figure 2) indicate that the abutments were filled almost entirely with masonry due to their height, as were the upper part of the arches and piers, making a curvature over which a $7 \mathrm{~cm}$ waterproof concrete layer was laid, marking the position of the holes to drain any water that filtered through the masonry. On top of this, masonry was filled to the top of the bridge, compacted earth was used as fill.

The result was a bridge $80 \mathrm{~m}$ long and $6.80 \mathrm{~m}$ wide, providing a passageway of $6 \mathrm{~m}$ for the movement of goods and source material. Also, it was a civil-engineering challenge for the time, serving for more than 150 years (Figure 4) and thus becoming part of the monumental heritage of Spain.

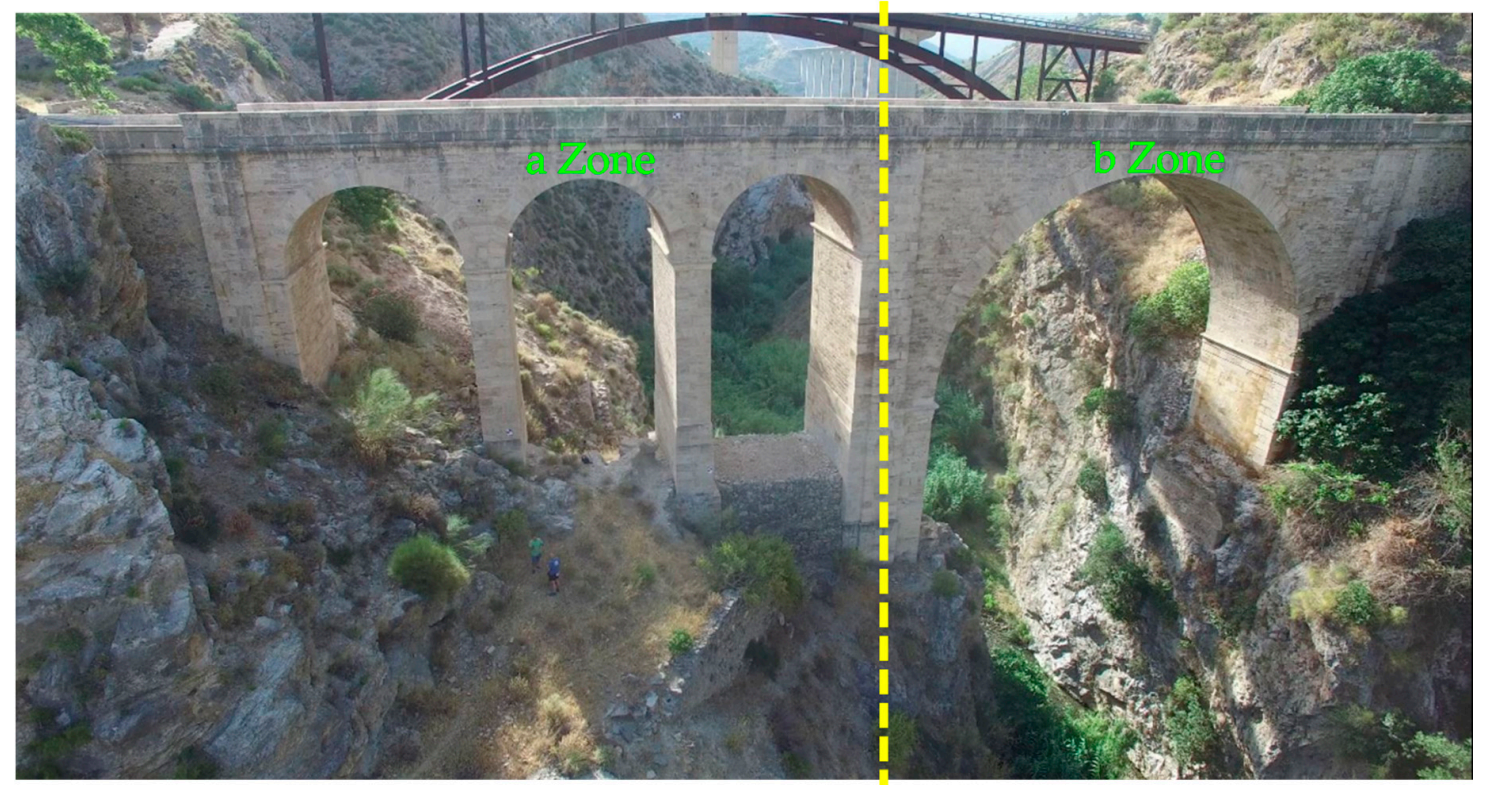

Figure 4. Ízbor bridge image taken by remotely a piloted aircraft system (RPAS). 


\section{Materials and Methods}

The methodology followed throughout this research is presented in Figure 5.

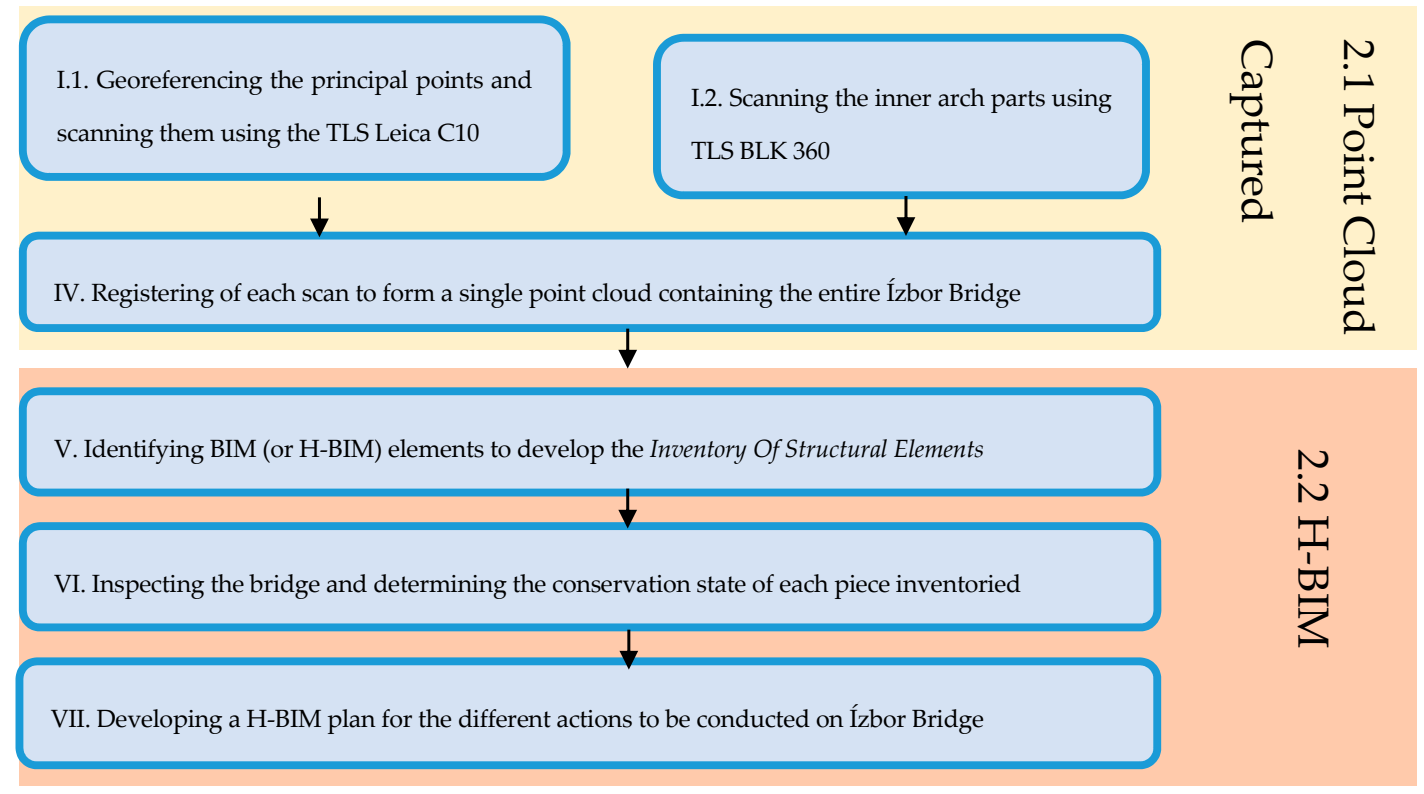

Figure 5. Workflow.

\subsection{Point Cloud Captured}

The point cloud (PC) is the basis for modeling the bridge. We used different instruments to survey the complete structure, which needed to be georeferenced for reliable documentation. The instruments used were: 1) A Leica GPS 1200 connected to a server that provided differential corrections from the RAP network (Red Andaluza de Posicionamiento); 2) a Leica TS02 total station with 3" angular accuracy and $1.5 \mathrm{~mm} \pm 2 \mathrm{ppm}$ distance accuracy; and 3) a Leica C10 laser scanner dual axis compensator with both the ability for stationing on known coordinate points and leveling. The $\mathrm{C} 10$ range was $300 \mathrm{~m}$; and lastly 4) a Leica BLK360 laser scanner with a $60 \mathrm{~m}$ range, no leveling ability but being lightweight and convenient for transporting.

We georeferenced the two station points IZB and IZB3 with GPS, which were the baseline to provide the UTM-30 coordinates in the ETRS89 system to the rest of the station points (Figure 6). With the total station placed in IZB1 $(454581.493,4083284.878,350.562)$ and orientating to IZB3 (454595.754, 4083363.241, 350.539), we provided ETRS89 UTM-30 coordinates to IZB4, IZB5, and IZB7, which are all in the upper part surrounding the bridge.

Most parts of the bridge were viewed from IZB1, IZB3, IZB4, IZB5, and IZB7 (we call these the "principal points") except for some of the inner parts of the arches. Because the distances between some principal points and the bridge were greater than the BLK30 range, we stationed the C10 laser scanner on the principal points. Each C10 station consisted of a positioning on a known coordinate point and an orientation to a target placed at another known coordinate point. After the $\mathrm{C} 10$ orientation, we proceeded to scan the bridge. The $\mathrm{C} 10$ station and orientation at the principal points registered a 3D vector error of less than $0.008 \mathrm{~m}$. The registration of the point cloud for the $\mathrm{C} 10$ scans was processed by the software Cyclone Register 9.1. 


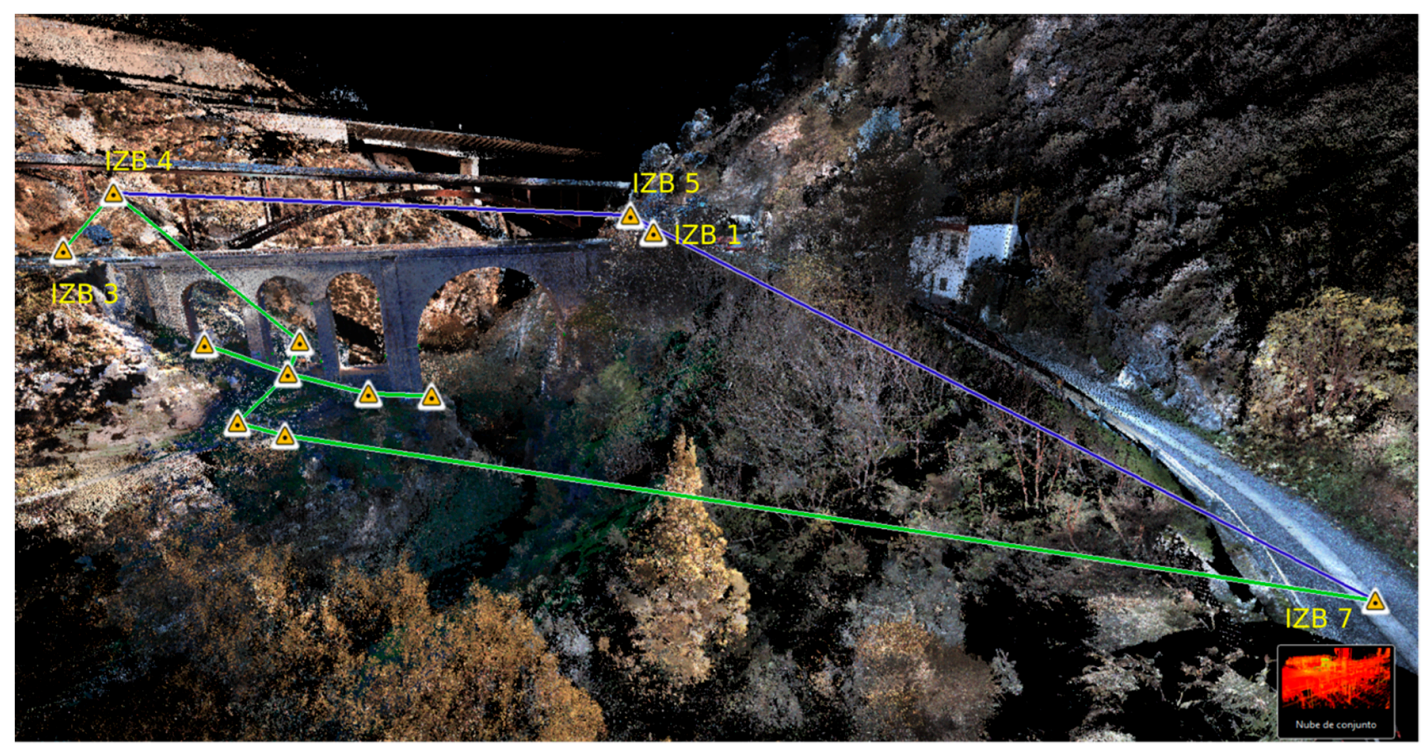

Figure 6. Scan stations ground distribution and the links between them (Point cloud).

The inner parts of the arches were captured with the laser scanner BLK 360 placed on the scan stations not labeled in Figure 6. We used the BLK360 because the access to the bottom of the bridge was so steep that it was not possible to transport the C10 load. For the registration of the BLK360 scan stations, we used targets (Figure 7), which appeared both in the BLK360 scan stations and in some of the C10 scan stations (Figure 6 shows a link between the IZB4 and a BLK360 and also between the IZB7 and another BLK360). The registration of the BLK360 scan stations was processed using the software Cyclone Register 360, and in all the cases the link error between two scan stations was less than $0.015 \mathrm{~m}$.

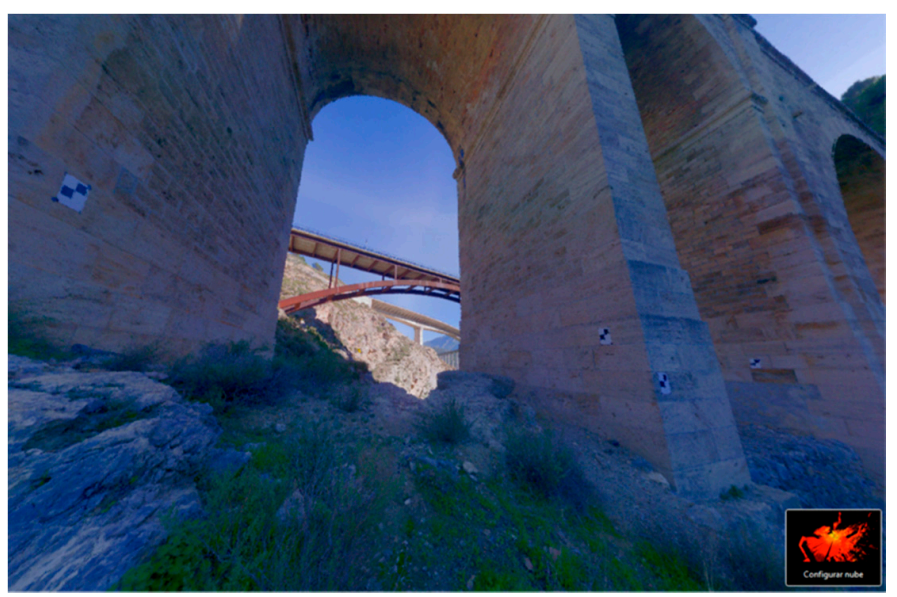

Figure 7. Targets used to register the BLK360 scan stations.

\subsection{Heritage Building Information Modeling (H-BIM)}

The PC captured can be incorporated into a BIM platform or database to serve as a base for modeling the different elements of the bridge using parametric objects of known geometry in a reverse engineering process. However, the main problem when modeling historical heritage is that its forms or shapes are not as standardized as modern or functional buildings, making it difficult to find certain libraries and tools in commercial BIM software that allow modeling immediately or automatically from the PC. Thus, the challenge is to build several families of parametric elements that allow the modeling of the complex and irregular forms comprising historical monuments. This is time consuming, but it allows us to create the libraries that will make up the H-BIM and that can be used in other projects. 
The creation of new libraries to be used for the H-BIM must take into consideration that the 3D model must allow the transition between the different scales at which it can be visualized, from a general view to the detail of a singular element. In this sense, we must plan the level of development (LoD) of each element, taking care that if the LoD is very high, the size of the files will also be high, slowing the management of the model. In this study, we had a $300 \mathrm{LoD}$ for all the bridge elements as defined by the organization BIMFORUM [24]: "the Model Element is graphically represented within the Model as a specific system, object or assembly in terms of quantity, size, shape, location, and orientation. Non-graphic information may also be attached to the Model Element."

Before beginning the modeling phase, we analyzed the existing bridge documentation in order to understand the different parts of the structure and the construction process. For this, the project drafted by the Ministry of Public Works of Spain in 1859 served as the starting point. This project provided bridge details that would not have been possible to detect with the exterior capture of its geometry, such as stone reinforcement of the arches or stirrups (Figure 2).

After the PC processing and the identification of the different parts of the bridge, we began the modeling using the commercial software Autodesk Revit. For this, it was necessary to create several families to model non-conventional forms such as the keystones of the arches, the ends of the piers, the parapets, and the interior stone reinforcements (Figure 8). In this respect, it is important to highlight that BIM is the work methodology, and the software is the tool.

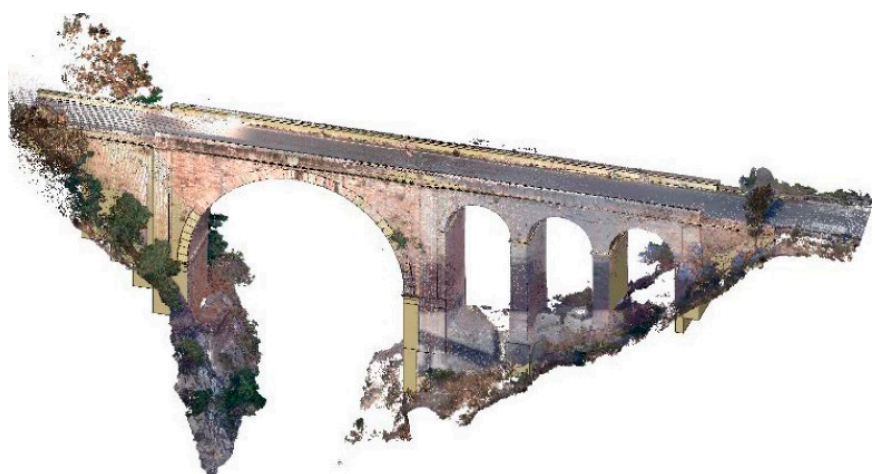

(a)

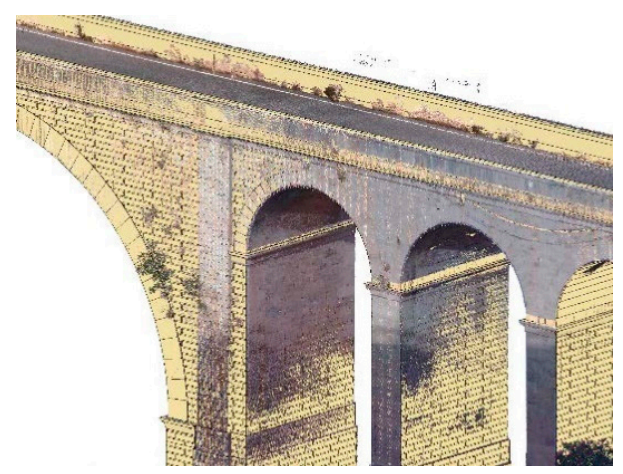

(b)

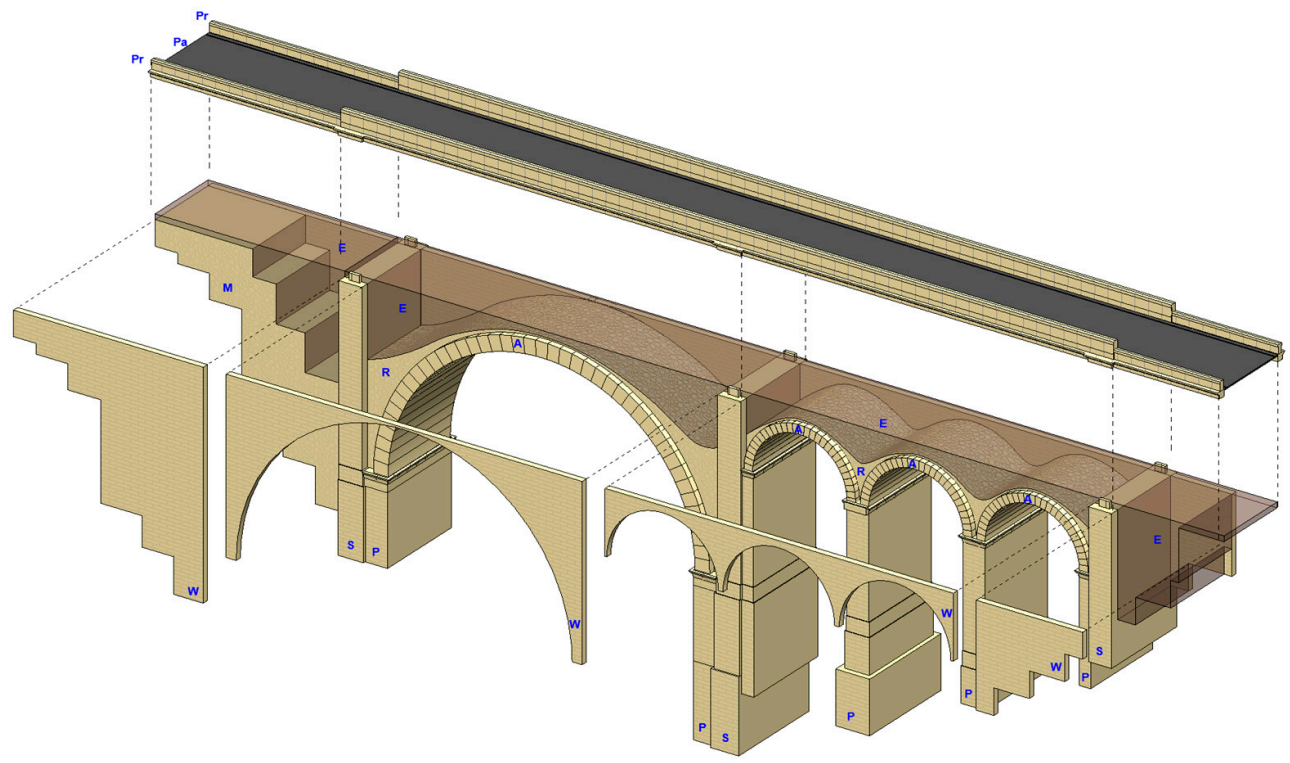

(c)

Figure 8. Ízbor bridge PC (Point Cloud) and the BIM (Building Information Modeling) model. (a) and (b) PC and modeling. (c) exploded view of Ízbor bridge BIM model. 
In the bridge modeling, in addition to defining each of its elements in 3D with its physical and constructive properties, the relationships between elements were established so that the performance of each of them was determined by its function within the set. In parametric modeling, these connections are established between the elements, providing coherence in the virtual model of the infrastructure under study. In the software used (Autodesk Revit), the geometry of the elements and their parameters are defined and controlled by families, which can be system families, loadable families, and in situ families. System families contain basic elements such as walls, piers, and beams, while loadable families define custom elements that can be used in several projects and families of in situ model elements that will be used only in the project under study.

The modeling of the bridge and the linking between elements required 12 levels to be defined: The abutments were modeled by wall-type families (blue in Figure 9); the piers by pier-type families (green); the voussoirs with beam-type families (red); the pavement by soil-type families (orange); the enclosures and parapets by wall-type families (not visible in Figure 9), there being a relationship between each of these elements. The stone fillings (yellow in Figure 9) and earth fillings (brown) were modeled by in situ families without connection to the rest of the structural elements.

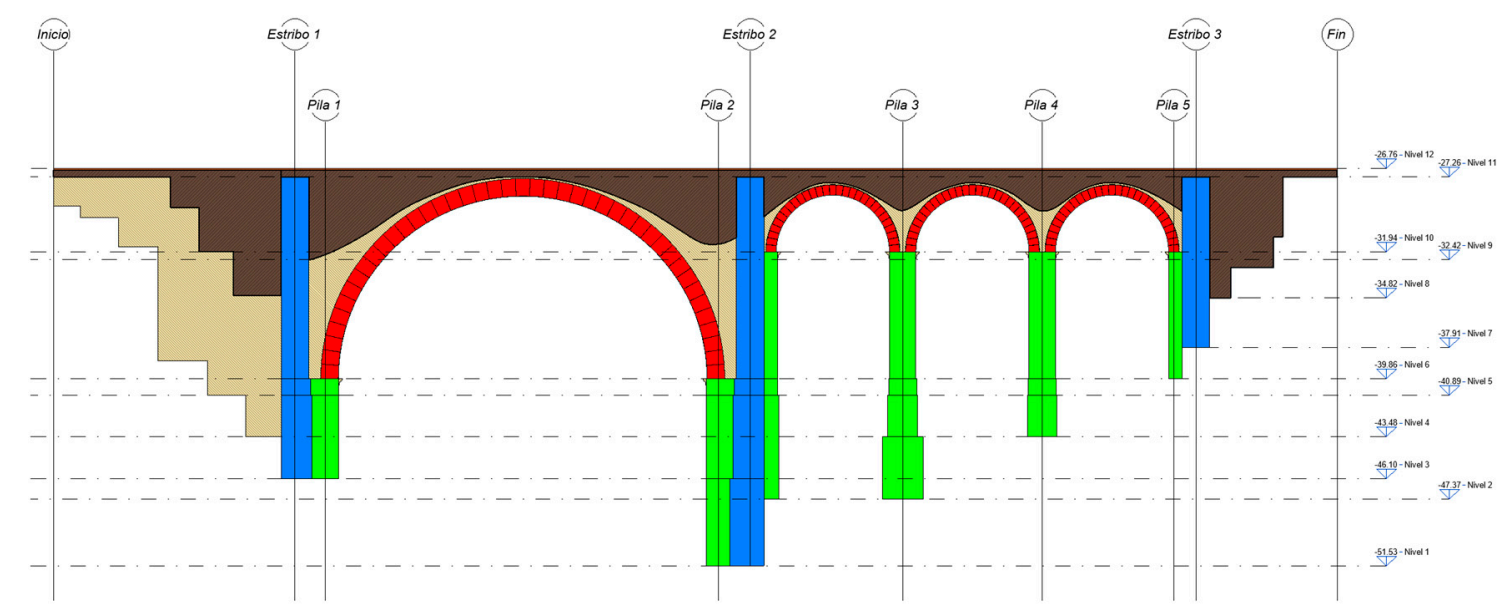

Figure 9. Bridge section by the longitudinal axis.

The inventory and labeling of the elements that conform the structure were made using two categories: elements and pieces. The elements considered were (Figure $8 \mathrm{c}$ ) piers $(\mathrm{P})$, stirrups $(\mathrm{S})$, arches (A), masonry filling $(\mathrm{M})$, walls $(\mathrm{W})$, earth filling $(\mathrm{E})$, parapets $(\mathrm{Pr})$ and pavements $(\mathrm{Pa})$, which are divided into pieces. In total, 28 elements and 188 pieces were inventoried.

To manage each part into which the bridge was divided, the following shared parameters were created: 1.1. Date of construction, 1.2. Project plans, 2.1. Element, 2.2. Piece, 2.3. Construction material and 2.4. Photography. The identification parameters of the Arc_1 element and the Dovela_5 piece is shown in Figure 10a. All the bridge pieces were dynamically compiled in a table entitled Inventory Of Structural Elements (Figure 10b), which can be edited and expanded according to the conservation needed. The parts were indicated using multi-category labels in which the element, the part, and the material appear (Figure 10c). 


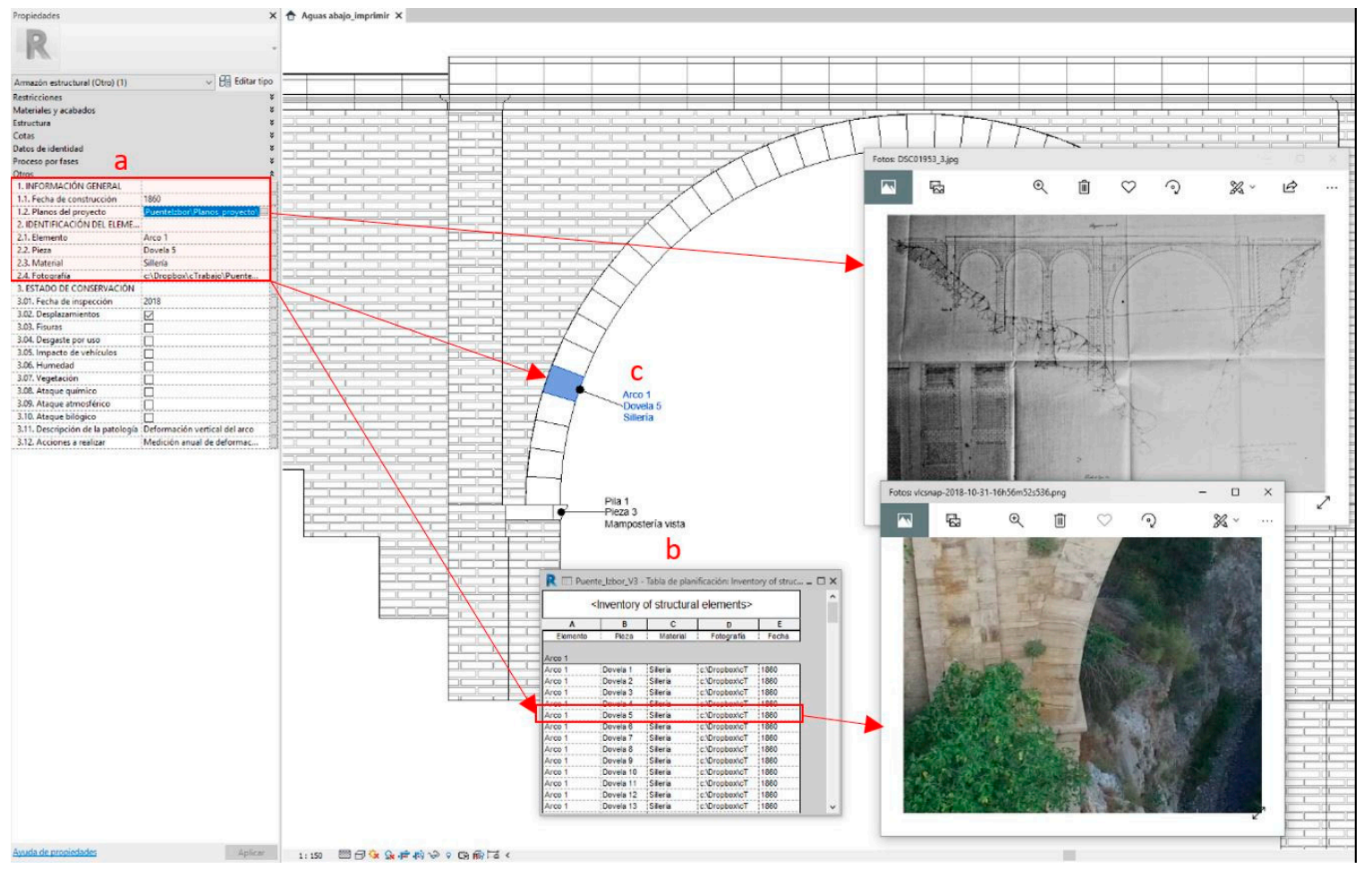

Figure 10. Identification and labeling of elements.

The identity of each element was completed with the result of the bridge inspection, the conservation state of each part inventoried through the following parameters (Figure 11): 3.1. Inspection date, 3.2. Displacements, 3.3. Fissures, 3.4. Wear by commissioning, 3.5. Impact of vehicles, 3.6. Moisture, 3.7. Vegetation, 3.8. Chemical attack, 3.9. Biological attack, 3.11. Pathology description and 2.12. Actions to be undertaken.

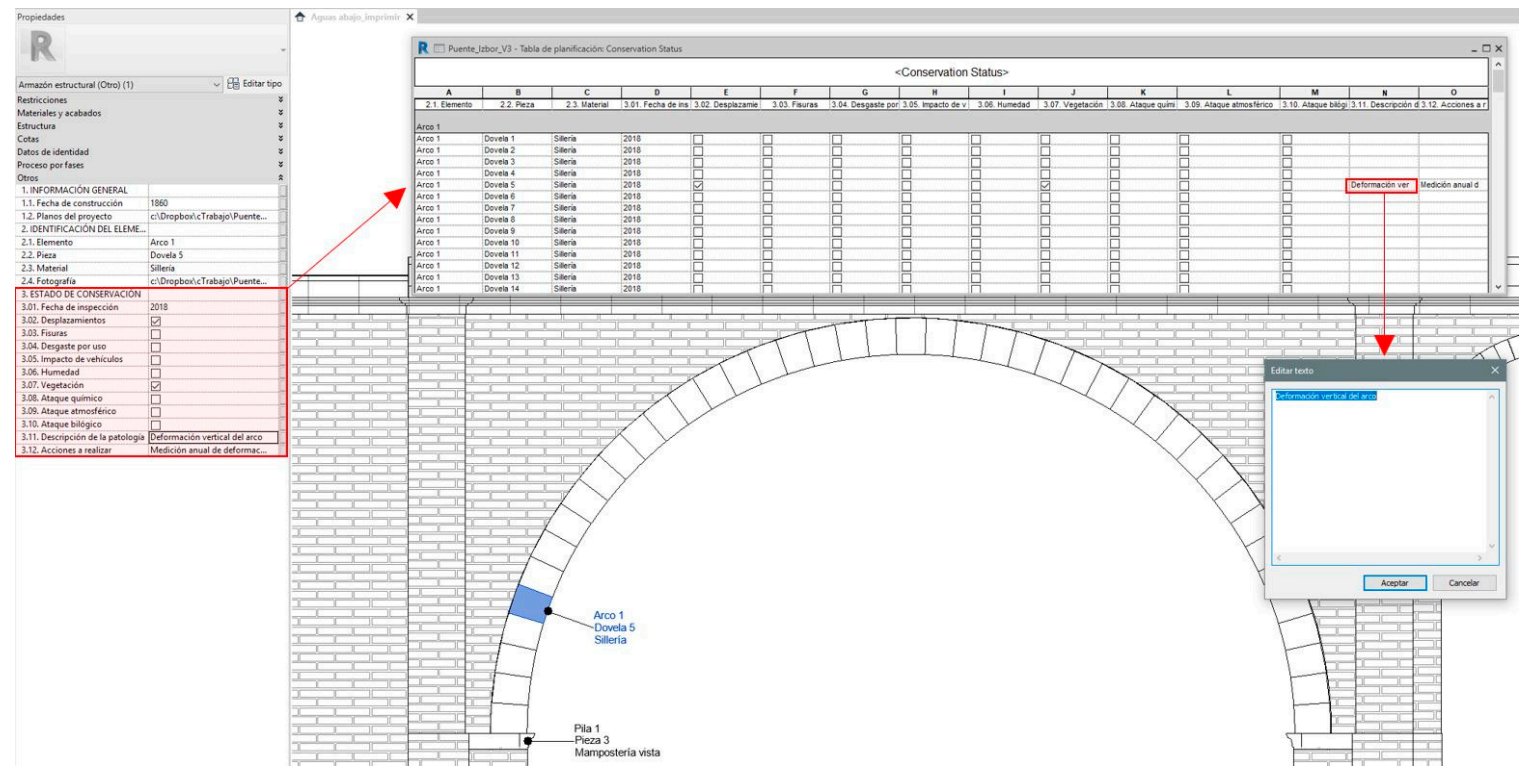

Figure 11. Inventory of the conservation states of the pieces. 
The final step of the H-BIM developed was to plan the different actions, using the BIM tools, which needed to be conducted on the bridge. For this, we defined the execution phases of any measure taken and the acquired state of any of the parts defined in this process (existing parts, demolition, temporary or new elements). In the case of Ízbor bridge, the structure was modeled according to the project prepared in 1860 (Phase 1860) and to the PC captured (Phase 2018). From this comparison, we detected the changes and deformations that had resulted over the previous 158 years.

Using the construction tools by phases, we recorded all the work performed on the bridge, and we planned the new conservation measures that were necessary, an account of these actions being a valuable resource for heritage management.

\section{Results and Discussion}

Our analysis of the Ízbor bridge demonstrates the possibility of using commercial BIM software (in this case Autodesk Revit) to model a historical bridge, despite the lack of libraries that include parametric elements capable of modeling the complex forms existing in the historical heritage, leading a great effort in the development of new families. Although, this project could be available to the community and could be used to for new projects, there is a broad field in which to conduct research concerning a collection of parametric families to solve the modeling of the several forms that are presented in this kind of construction.

However, the modelling of Ízbor bridge can serve as the starting point to analyze the possibility of conserving and maintaining the historic monument by creating what we call Heritage Building Information Modeling (H-BIM). The proposed H-BIM part of the inventory of the bridge classifies different elements and pieces, assigning them a number of parameters related to their construction date, material, photography, etc. The elements, pieces, and their parameters are dynamically reflected before any change in an inventory table of structural elements, being a one-to-one link between the selection of non-graphic data and the geometric model.

From the inventory of the different parts of the bridge, new parameters were created regarding the state of conservation and the actions to be carried out on each part. These parameters and their associated table can be fully configured, depending on the needs of the different disciplines involved in the management of the bridge. Unlike the creation of the model, this phase does not require the user in charge of conservation management to be a BIM specialist.

Likewise, the possibility of having a temporal record for the variations that the parameters defined in each of the parts may undergo, enables us to plan new conservation measures in order to avoid future pathologies. In this way, the HBIM indicates the state of conservation and the operations conducted on the infrastructure throughout its life cycle, creating what could be considered to be a time capsule of the bridge.

For example, the central arch was built with a radius of $11.5 \mathrm{~m}$, while in 2018 it had deformed to a semi-major ellipse of $11.5 \mathrm{~m}$ and semi-axis smaller than $11.39 \mathrm{~m}$, lowering the keystone of the arch 0.11 $\mathrm{m}$ (Figure 12). 


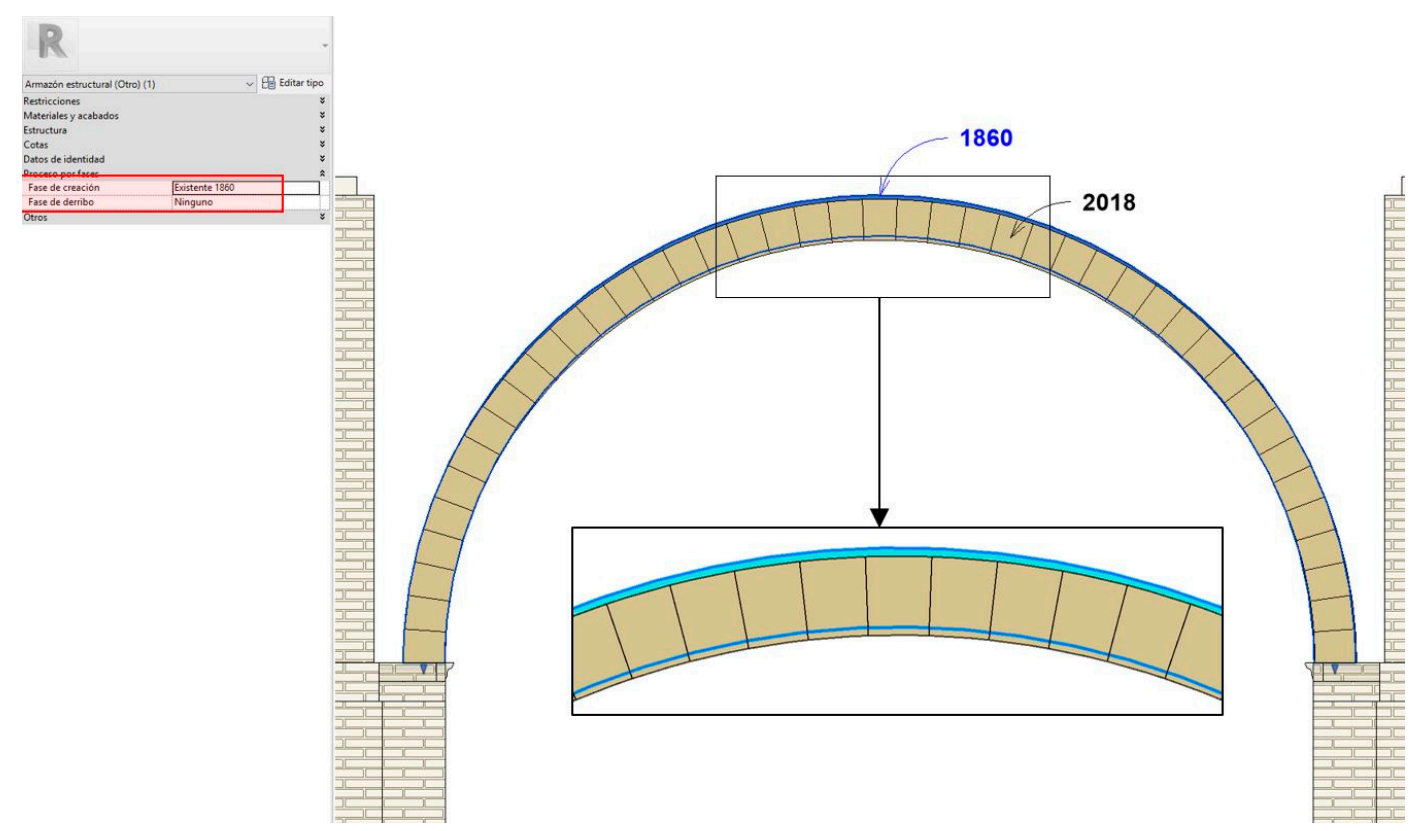

Figure 12. Use of the execution phases to register the central arch in 1860 and 2018.

Furthermore, the bridge was analyzed for verticality. For this, the following process was followed: (1) the PC was sliced to determine some parts that, a priori, formed two planes (one for the PC of the downstream portion of the bridge and another for the PC of the upstream portion of the bridge). (2) Afterwards, the plane best fitted to the previous PC was generated. (3) Finally, given that the PC was leveled, the inclination angle of the normal vector of each plane was measured with respect to the world axes, indicating that the two planes formed 90.1 sexagesimal degrees with respect to the axis (Figure 13). This value reveals a discordant inclination of 0.1 sexagesimal degrees. Nevertheless, the Ízbor bridge cannot be said to be leaning, as this minor inclination of the planes may be due to the errors inherent in the measurement process.

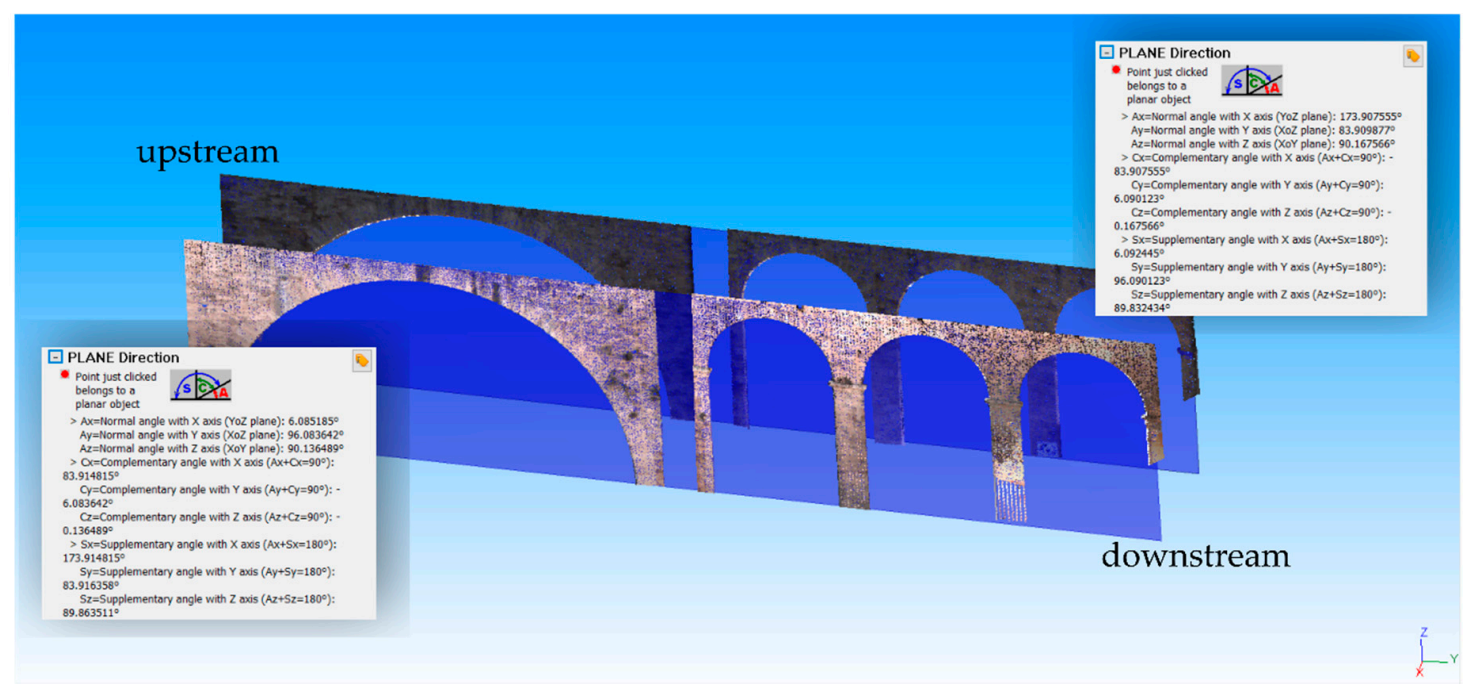

Figure 13. Best-fitted upstream plane and best-fitted downstream plane. Attached boxes gives information about each plane direction.

According to the bridge platform, we performed a geometric analysis based on the resulting PC. For this, we generated the best-fitted plane and we computed the distance from the plane to the PC 
(Figure 14), observing that two zones were raised approximately $5 \mathrm{~cm}$ above the adjustment plane. This may be due to platform sets or due to the design camber in the project.

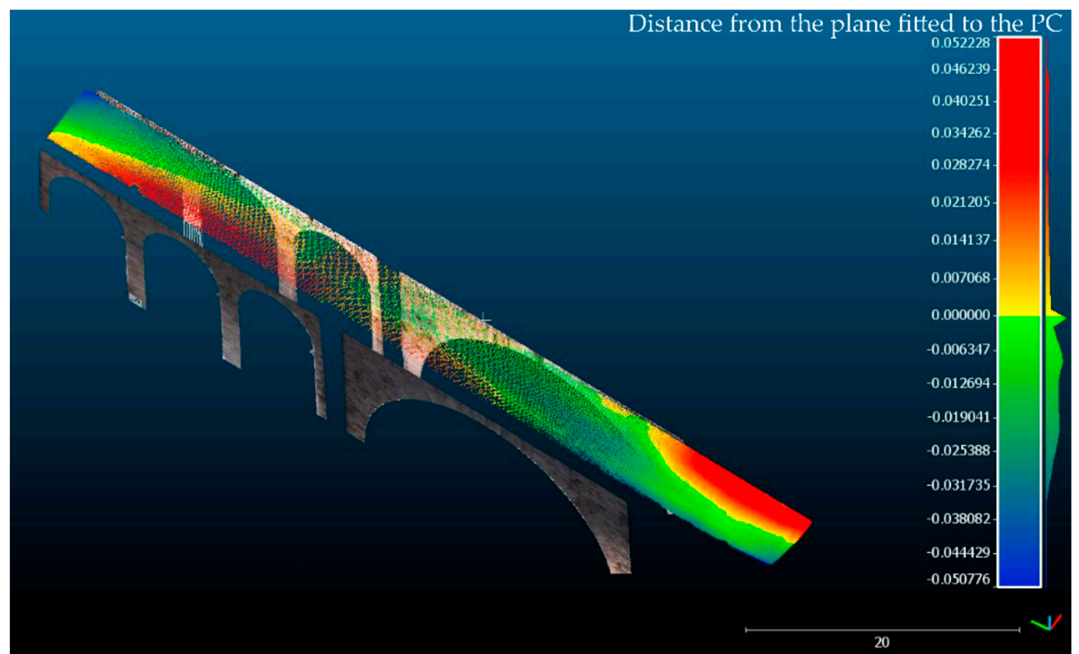

Figure 14. Distances from the plane best fitted to the PC captured to detect deformations.

\section{Conclusions}

We have developed a BIM model of a singular civil-engineering structure, a stone bridge, using a commercial BIM software called Revit. During the BIM process, we found that conventional commercial BIM software can be used to generate BIM models of complex structures or morphologies, but we have encountered great difficulties in doing so because only a few families of libraries are dedicated to the modeling of complex civil constructions such as bridges.

H-BIM could be the starting point for management, conservation, and maintenance tasks in historic monuments such as this bridge. Thus, H-BIM could be used throughout the life cycle of a bridge: temporary series of georeferenced PC will document the geometric state on different dates; the analysis and pathologies detected could be incorporated into the inventory; work performed could be registered in suitable attributes. This makes it possible to establish the actions to be performed on any part of the monument in the future.

According to the results in the analysis referring to the bridge deformations, we have found that: (1) The central arch was built according to a circumference of $11.5 \mathrm{~m}$ radius, while in 2018 it had become deformed to a semi-major ellipse of $11.5 \mathrm{~m}$ and a smaller semi-axis of $11.39 \mathrm{~m}$, lowering the keystone by $0.11 \mathrm{~m}$; (2) verticality had not changed, given that, although we measured a 0.1 degree tilt, this could have been caused by the inherent error of the PC. These findings should be incorporated in the parameters corresponding to the state of conservation, particularly to displacements and inspection dates.

The H-BIM proposed in this manuscript will be improved in the future according to the results of new analyses to be made on additional heritage bridges.

Author Contributions: All the authors (Carlos A. León-Robles, Juan F. Reinoso-Gordo and Juan J. GonzálezQuiñones) took part in the entire researching process. All the authors participated collecting the scanner data and analyzing the BIM model. All the authors designed and built the BIM bridge and wrote the text. All the authors analyzed and compared the point cloud and the BIM bridge. The discussion and conclusions were debated and agreed by the group.

Funding: This research received no external funding.

Acknowledgments: Ministry of Public Works (road demarcation in Granada, Spain) supplied the ancient construction plans of the stone bridge.

Conflicts of Interest: The authors declare no conflicts of interest. 


\section{References}

1. Murphy, M.; Corns, A.; Cahill, J.; Eliashvili, K.; Chenau, A.; Pybus, C.; Shaw, R.; Devlin, G.; Deevy, A.; Truong-Hong, L. Developing historic building information modelling guidelines and procedures for architectural heritage in Ireland. In Proceedings of the The International Archives of the Photogrammetry, Remote Sensing and Spatial Information Sciences, Ottawa, Canada, 1 August 2017; Volume XLII-2/W5, pp. 539-546.

2. Logothetis, S.; Delinasiou, A.; Stylianidis, E. Building information modelling for cultural heritage: A review. In Proceedings of the ISPRS Annals of the Photogrammetry, Remote Sensing and Spatial Information Sciences, 25th International CIPA Symposium, Taipei, Taiwan, 31 August-4 September 2015.

3. Osello, A.; Lucibello, G.; Morgagni, F. HBIM and virtual Tools: A new chance to preserve architectural heritage. Buildings 2018, 8, 12. [CrossRef]

4. Stober, D.; Žarnić, R. Application of HBIM as a research tool for historical building assessment. Civ. Eng. J. 2018, 4, 7 .

5. Bianchini, C.; Inglese, C.; Ippolito, A. The role of BIM (building information modeling) for representation and managing of built and historic artifacts. Disegnarecon 2016, 9, 10-11.

6. Bianchini, C.; Nicastro, S. The definition of the level of reliability: A contribution to the transparency of historical-bim processes. Dienne 2018, 2, 46-60.

7. López, F.; Lerones, P.; Llamas, J.; Gómez-García-Bermejo, J.; Zalama, E. A review of heritage building information modeling (H-BIM). Multimodal Technol. Interact. 2018, 2, 21. [CrossRef]

8. Succar, B. Building information modelling framework: A research and delivery foundation for industry stakeholders. Autom. Constr. 2009, 18, 357-375. [CrossRef]

9. King, T.F. The Archaeological Survey: Methods and Uses; Heritage Conservation and Recreation Service, U.S. Department of the Interior: Washington, DC, USA, 1978.

10. Garagnani, S.; Manferdini, A.M. Parametric accuracy: Building information modeling process applied to the cultural heritage preservation. Int. Arch. Photogrammetr. Remote Sens. Sp. Inf. Sci. 2013, XL-5/W1, 87-92.

11. Murphy, M.; McGovern, E.; Pavia, S. Historic building information modelling-adding intelligence to laser and image based surveys. ISPRS J. Photogrammetr. Remote Sens. 2013, 76, 89-102.

12. Barber, D.; Mills, J. 3D Laser Scanning for Heritage. Advice and Guidance to Users on Laser Scanning in Archaeology and Architecture, 2nd ed.; Historic England: Swindon, UK, 2007.

13. Anil, E.B.; Tang, P.; Akinci, B.; Huber, D. Deviation analysis method for the assessment of the quality of the as-is building information models generated from point cloud data. Autom. Constr. 2013, 35, 507-516. [CrossRef]

14. Snavely, N.; Seitz, S.M.; Szeliski, R. Modeling the world from internet photo collections. Int. J. Comput. Vis. 2008, 80, 189-210. [CrossRef]

15. Pritchard, D.; Sperner, J.; Hoepner, S.; Tenschert, R. Terrestrial laser scanning for heritage conservation: The cologne cathedral documentation project. ISPRS Ann. Photogramm. Remote Sens. Spat. Inf. Sci 2017, 4. [CrossRef]

16. Shanoer, M.M.; Abed, F.M. Evaluate 3D laser point clouds registration for cultural heritage documentation. Egypt. J. Remote Sens. Sp. Sci. 2018, 21, 295-304. [CrossRef]

17. Rodríguez-Moreno, C.; Reinoso-Gordo, J.F.; Rivas-López, E.; Gómez-Blanco, A.; Ariza-López, F.J.; Ariza-López, I. From point cloud to BIM: An integrated workflow for documentation, research and modelling of architectural heritage. Surv. Rev. 2018, 50, 212-231. [CrossRef]

18. Reinoso-Gordo, J.; Rodríguez-Moreno, C.; Gómez-Blanco, A.; León-Robles, C. Cultural heritage conservation and sustainability based on surveying and modeling: The case of the 14th century building Corral del Carbón (Granada, Spain). Sustainability 2018, 10, 1370. [CrossRef]

19. Cheng, L.; Chen, S.; Liu, X.; Xu, H.; Wu, Y.; Li, M.; Chen, Y.; Cheng, L.; Chen, S.; Liu, X.; et al. Registration of laser scanning point clouds: a review. Sensors 2018, 18, 1641. [CrossRef]

20. Meydenbauer, A. Handbuch der Meßbildkunst in Anwendung auf Baudenkmäler und Reiseaufnahmen; Knapp Verlag: Halle, Germany, 1912.

21. Westoby, M.J.; Brasington, J.; Glasser, N.F.; Hambrey, M.J.; Reynolds, J.M. 'Structure-from-Motion' photogrammetry: A low-cost, effective tool for geoscience applications. Geomorphology 2012, 179, 300-314. [CrossRef] 
22. Lowe, D.G. Distinctive image features from scale-invariant keypoints. Int. J. Comput. Vis. 2004, 60, 91-110. [CrossRef]

23. Klein, L.; Li, N.; Becerik-Gerber, B. Imaged-based verification of as-built documentation of operational buildings. Autom. Constr. 2012, 21, 161-171. [CrossRef]

24. BIMforum 2013. Available online: http://bimforum.org/wp-content/uploads/2013/08/2013-LODSpecification.pdf (accessed on 5 November 2018). 